\title{
A STUDY ON RELATIONSHIP OF BODY MASS INDEX (BMI) AND WAIST-TO-HIP RATIO (WHR) TO CORONARY ARTERY DISEASE RISK FACTORS IN CASES AND CONTROLS
}

\author{
Veena S. Harwalkar1, Trimal Kulkarni²
}

${ }_{1}^{1}$ Assistant Professor, Department of Anatomy, Al-Ameen Medical College and Hospital, Vijayapur, Karnataka. ${ }^{2}$ Senior Resident, Department of Paediatrics, Al-Ameen Medical College and Hospital, Vijayapur, Karnataka.

ABSTRACT

\section{BACKGROUND}

Over the past decade or more, the prevalence of traditional risk factors for cardiovascular diseases has been increasing in the developing world including China and India with consequent increases in the rates of coronary and cerebrovascular events. The objective of this study is to study the role of anthropometric indices (BMI and WHR) with coronary artery disease risk factors in the occurrence of coronary artery disease (CAD).

\section{MATERIALS AND METHODS}

Total sample size of present study was 200 subjects. In 200 subjects, 100 CAD cases and 100 controls (without CAD) aged between 20 - 60 years were included. Each subject was examined for height, weight to measure body mass index (BMI) and waist, hip circumferences to measure waist: hip ratio (WHR) as per standard cardiovascular survey methods. Subjects who have been diagnosed to have CAD in any form were selected in the study as cases (Group I). Subjects who have attended general outpatient department, but without proven CAD were selected in the study as controls (Group II).

\section{RESULTS}

Age distribution was non-significantly more in Group I when compared to Group II with $p<0.525$. Males were significantly more in Group I when compared to Group II with $\mathrm{p}<0.048$. BMI distribution was significantly more in Group I when compared to Group II with $\mathrm{p}<0.001$. Waist circumference was significantly more in Group I compared to Group II with $\mathrm{p}<0.005$. Hip circumference was not significant in Group I compared to Group II with $\mathrm{p}<0.121$. WHR was significantly more in Group I compared to Group II with $\mathrm{p}$ $<0.001$.

\section{CONCLUSION}

Anthropometric variables BMI, hip circumference and WHR in both genders were significantly affected in subjects with coronary risk factors. It may be a simple measure to identify those having these risk factors and subject them to appropriate interventions.

\section{KEYWORDS}

Body Mass Index, Waist-to-Hip Ratio, Coronary Artery Disease, Descriptive Comparative Study.

HOW TO CITE THIS ARTICLE: Harwalkar VS, Kulkarni T. A study on relationship of body mass index (BMI) and waist-to-hip ratio (WHR) to coronary artery disease risk factors in cases and controls. J. Evolution Med. Dent. Sci. 2017;6(78):5519-5523, DOI: $10.14260 /$ Jemds/2017/1199

\section{BACKGROUND}

Studies show that at the beginning of the 20th century, coronary heart disease (CHD) accounted for less than $10 \%$ of all deaths worldwide. At the beginning of the 21st century, CHD accounts for nearly $50 \%$ of all deaths in the developed world and $25 \%$ in developing countries such as India. ${ }^{1}$ Overall prevalence increased from Coronary artery disease (CAD) has been $2.06 \%$ in 1970 to $5 \%$ in 2002 in rural area and $1.04 \%$ in early 1960 to $13.02 \%$ in 2004 in urban area. ${ }^{2}$ Coronary artery disease (CAD) has been defined as "impairment of heart function due to inadequate blood flow to the heart compared to its needs, caused by obstructive changes in the coronary circulation to the heart."

Financial or Other, Competing Interest: None.

Submission 04-07-2017, Peer Review 16-09-2017,

Acceptance 21-09-2017, Published 28-09-2017.

Corresponding Author:

Dr. Veena S. Harwalkar,

Assistant Professor

Department of Anatomy,

Al-Ameen Medical College and Hospital,

Vijayapur-586 108, Karnataka, India.

E-mail: veena3447@gmail.com

DOI: $10.14260 /$ jemds $/ 2017 / 1199$

(c) $(7)$
CAD manifests itself in many presentations like: Angina pectoris of effort, myocardial infarction, irregularities of the heart, cardiac failure and sudden death. ${ }^{3}$ Coronary artery disease is a multifactorial disease. There are many modifiable and non-modifiable risk factors associated with CAD, which may be generalised or systemic. ${ }^{4}$ Behavioural risk factors such as smoking, lack of exercise, high fat containing diet, stress, hyperlipidaemic status, alcohol intake are well known modifiable risk factors, whereas age, male sex and positive family history are non-modifiable risk factors of cardiovascular disease. A combination of risk factors has been shown to increase the risk of occurrence of these diseases. ${ }^{5}$ Simple anthropometric index like Body mass index (BMI), Waist circumference (WC), Hip circumference (HC) and WHR (waist: hip ratio) plays an important role in clinical practice in predicting the development of CAD risk factors. Despite the modern techniques, anthropometric measurements are traditionally important methods to study the genetic structure and prediction of risk factors of many complex diseases in human health. Both height and weight are influenced by genetic, environmental and socio-economic factors and are associated with other coronary risk factors. ${ }^{6}$ In the ageing population of industrialised nations, increasing burden of CAD has an enormous impact on population health, the health care system and the economy. The need for a 
better understanding of how to achieve "healthy ageing," how to slow down the process of cardiovascular disease generation and progression and how to improve preventive and therapeutic strategies is obvious in society with a steadying rising life expectancy. Therefore, the present study was done to elucidate the relationship of simple anthropometric indices BMI and WHR with coronary artery disease; it may help to facilitate enhanced screening for disease risk.

\section{MATERIALS AND METHODS}

\section{Sample Size}

For the convenience, sample size of 200 subjects were chosen for the study. Two hundred subjects were divided into two groups such as Group I: 100 coronary artery disease cases and Group II: 100 controls without coronary artery disease aged between 20 - 60 years.

A descriptive comparative study was done from January to December 2012 involving 100 cases and 100 controls of both gender between the age of 20 and 60 years. The study population was selected from Basaweshwar teaching and general hospital attached to HKE's M.R. Medical College, Kalburgi, Karnataka, India. The study was approved by Institutional Ethics Committee of HKE's M.R. Medical College Kalburgi, Karnataka. Detailed and signed informed consent was obtained from the subjects in the presence of witness, after oral reading of the protocol in verbatim and explaining it in the subject's own language.

\section{Cases (Group I)}

One hundred patients between 20 and 60 years who have been diagnosed to have coronary artery disease (CAD) in any form were selected in the study. To diagnose CAD, electrocardiography of patients along with supportive investigations like lipid profile ${ }^{7}$ was taken.

\section{Controls (Group II)}

One hundred subjects between 20 and 60 years who attended general outpatient department, but without proven CAD were selected in the study.

\section{Inclusion Criteria}

Patients with coronary artery disease of age group of 20 and 60 years were selected for the study as cases. Subjects between 20 to 60 years male or female attending general outpatient department for any other complaint were selected for study as controls. At the onset, the study protocol was briefed and those who came forward voluntarily to participate were included.

\section{Exclusion Criteria}

Subjects less than 20 years and more than 60 years were not included in the study. Patients who were proved not to have CAD either clinically or by any diagnostic aid were not included as cases.

\section{Anthropometric Measurements}

Each subject was examined for height, weight, WC and hip circumference without shoes and chappals with minimal clothing as per cardiovascular survey methods. ${ }^{8}$ Body mass index (BMI) was derived by Quetelet's Index. ${ }^{9}$ Waist circumference (WC) was measured such as midway between lateral lower ribs and iliac crest after gentle expiration, while patient was standing (in centimetres). Hip circumference (HC) was noted such as widest diameter over greater trochanter using non-elastic measuring tape (in centimetres). WHR (waist: hip ratio) was calculated by using the values of waist circumference (WC) and hip circumference (HC) calculated above.

\section{Statistical Analysis}

Descriptive and inferential statistical analysis has been carried out in the present study. Results on continuous measurements are presented on Mean \pm SD and results on categorical measurements were presented in number (\%). Significance was assessed at $5 \%$ level of significance. The following assumptions on data were made, Assumption 1: Dependent variables should be normally distributed; Assumption 2: Samples drawn from the population should be random, cases of the samples should be independent. Student ' $\mathrm{t}$ ' test (two tailed, independent) has been used to find the significance of study parameters. Fisher exact test has been used to find the homogeneity of samples on categorical scale.

\section{RESULTS}

Mean age in cases was $49.85 \pm 7.25$ years and mean age in controls was $50.75 \pm 6.15$ years. Age distribution was nonsignificantly less in Group I when compared to Group II with $\mathrm{p}=0.525$ (Table 1$)$.

\begin{tabular}{|c|c|c|c|c|}
\hline \multirow{2}{*}{$\begin{array}{c}\text { Age } \\
\text { (In Years) }\end{array}$} & \multicolumn{2}{|c|}{ Group I } & \multicolumn{2}{c|}{ Group II } \\
\cline { 2 - 5 } & No & $\mathbf{\%}$ & No & \% \\
\hline $20-30$ & 1 & 1.0 & 0 & 0.0 \\
\hline $31-40$ & 9 & 9.0 & 9 & 9.0 \\
\hline $41-50$ & 51 & 51.0 & 51 & 51.0 \\
\hline $51-60$ & 39 & 39.0 & 40 & 40.0 \\
\hline Total & $\mathbf{1 0 0}$ & $\mathbf{1 0 0 . 0}$ & $\mathbf{1 0 0}$ & $\mathbf{1 0 0 . 0}$ \\
\hline Mean \pm SD & $49.85 \pm 7.25$ & $50.75 \pm 6.15 \mathrm{NS}$ \\
\hline Table 1. Relationship between Age Distributions among \\
Study Groups \\
\hline
\end{tabular}

No: Number of subjects; \%: Percentage; SD: Standard deviation. Group I: Coronary artery disease cases; Group II: Subjects without CAD (controls). Age distribution nonsignificantly (NS) differ from respective group $(\mathrm{p}<0.05)$ (Paired t-test done).

Male subjects were in Group I (cases) 70 and in Group II (controls) 56 in numbers. Males were significantly more in Group I when compared to Group II with $p=0.048$. These results depict males were more significantly affected. In case of female subjects, in Group I (cases) 30 and in Group II (controls) 44 in numbers. Females were significantly more in Group II when compared to Group I with $p=0.623$ (Figure 1). These results depict males were more significantly affected compared to females. 


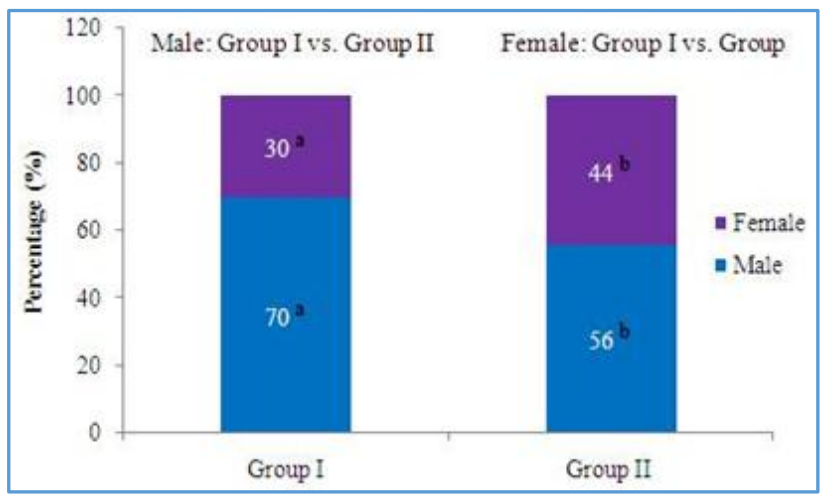

Figure 1. Relationship between Gender Distributions among Study Groups

Group I: Coronary artery disease cases; Group II: Subjects without CAD (controls). Gender distribution significantly differ from respective group (values with different superscripts ' $a$, b' were significantly different from each other $\mathrm{p}<0.05$ ) (Fisher exact test done).

Mean body mass index (BMI) in Group I (cases) was 27.89 $\mathrm{kg} / \mathrm{m}^{2}$ and mean height in Group II (controls) was 25.34 $\mathrm{kg} / \mathrm{m}^{2}$. BMI distribution was significantly more in Group I when compared to Group II with $\mathrm{p}<0.001$ (Table 2). Our results showed BMI to be a strong predictor of coronary artery disease.

\begin{tabular}{|c|c|c|c|c|}
\hline \multirow{2}{*}{$\begin{array}{c}\text { BMI } \\
\left(\mathbf{k g} / \mathbf{m}^{\mathbf{2}} \mathbf{)}\right.\end{array}$} & \multicolumn{2}{|c|}{ Group I } & \multicolumn{2}{c|}{ Group II } \\
\cline { 2 - 5 } & $\mathbf{N o}$ & $\mathbf{\%}$ & No & $\mathbf{\%}$ \\
\hline$<24.9$ & 19 & 19.0 & 36 & 36.0 \\
\hline $25-30$ & 63 & 63.0 & 62 & 62.0 \\
\hline$>30$ & 18 & 18.0 & 2 & 2.0 \\
\hline Total & $\mathbf{1 0 0}$ & $\mathbf{1 0 0 . 0}$ & $\mathbf{1 0 0}$ & $\mathbf{1 0 0 . 0}$ \\
\hline Mean \pm SD & $27.89 \pm 3.76^{\mathrm{a}}$ & $25.34 \pm 3.08^{\mathbf{b}}$ \\
\hline Table 2. Relationship between BMI distributions among \\
Study Groups \\
\hline
\end{tabular}

No: Number of subjects; \%: Percentage; SD: Standard deviation. Group I: Coronary artery disease cases; Group II: Subjects without CAD (controls). BMI distribution significantly differ from respective group (values with different superscripts 'a, b' were significantly different from each other $\mathrm{p}<0.05$ ) (Paired t-test done).

Mean waist circumference in Group I (cases) was 97.12 $\mathrm{cm}$ and in Group II (controls) was $93.42 \mathrm{~cm}$. Waist circumference was significantly more in Group I compared to Group II with $p<0.005$ (Table 3). This study showed that waist circumference is to be associated with development of coronary artery disease.

\begin{tabular}{|c|c|c|c|c|}
\hline Waist Circumference & \multicolumn{2}{|c|}{ Group I } & \multicolumn{2}{c|}{ Group II } \\
\cline { 2 - 5 } (cm) & No & $\mathbf{\%}$ & No & \% \\
\hline $80-90$ & 36 & 36.0 & 54 & 54.0 \\
\hline $91-100$ & 18 & 18.0 & 17 & 17.0 \\
\hline$>100$ & 46 & 46.0 & 29 & 29.0 \\
\hline Total & $\mathbf{1 0 0}$ & $\mathbf{1 0 0 . 0}$ & $\mathbf{1 0 0}$ & $\mathbf{1 0 0 . 0}$ \\
\hline \multicolumn{2}{|c|}{$97.12 \pm 3.36^{\mathrm{a}}$} & $93.42 \pm 8.93^{\mathrm{b}}$ \\
\hline \multicolumn{3}{|c|}{ Table 3. Relationship between Waist Circumference } \\
distributions among Study Groups \\
\hline
\end{tabular}

No: Number of subjects; \%: Percentage; SD: Standard deviation. Group I: Coronary artery disease cases; Group II: Subjects without CAD (controls). Waist circumference distribution significantly differ from respective group (values with different superscripts ' $a$, b' were significantly different from each other $\mathrm{p}<0.05$ ) (Paired t-test done).

Mean hip circumference is statistically similar in two groups with $\mathrm{p}=0.121$. Mean hip circumference in cases (Group I) was $100.67 \mathrm{~cm}$ and mean hip circumference in controls (Group II) was $98.97 \mathrm{~cm}$ (Table 4). This study showed that hip circumference is not being a predictor of coronary artery disease.

\begin{tabular}{|c|c|c|c|c|}
\hline \multirow{2}{*}{$\begin{array}{c}\text { Hip Circumference } \\
\text { (cm) }\end{array}$} & \multicolumn{2}{|c|}{ Group I } & \multicolumn{2}{c|}{ Group II } \\
\cline { 2 - 5 } & No & $\%$ & No & $\%$ \\
\hline $81-90$ & 17 & 17.0 & 22 & 22.0 \\
\hline $91-100$ & 24 & 24.0 & 41 & 41.0 \\
\hline$>100$ & 59 & 59.0 & 37 & 37.0 \\
\hline Total & $\mathbf{1 0 0}$ & $\mathbf{1 0 0 . 0}$ & $\mathbf{1 0 0}$ & $\mathbf{1 0 0 . 0}$ \\
\hline Mean \pm SD & $100.67 \pm 9.20$ & $98.97 \pm 9.76^{\mathrm{NS}}$ \\
\hline Table 4. Relationship between Hip Circumference \\
distributions among Study Groups \\
\hline
\end{tabular}

No: Number of subjects; \%: Percentage; SD: Standard deviation. Group I: Coronary artery disease cases; Group II: Subjects without CAD (controls). Hip circumference distribution non-significantly (NS) differ from respective group $(\mathrm{p}<0.05)$ (Paired t-test done).

Mean WHR in Group I (cases) was 0.96 and in Group II (Controls) was 0.94 . WHR was significantly more in Group I compared to Group II with $\mathrm{p}<0.001$ (Table 5). This study showed that WHR is to be associated with development of coronary artery disease.

\begin{tabular}{|c|c|c|c|c|}
\hline \multirow{2}{*}{ WHR } & \multicolumn{2}{|c|}{ Group I } & \multicolumn{2}{c|}{ Group II } \\
\cline { 2 - 5 } & No & $\mathbf{\%}$ & No & $\%$ \\
\hline$<0.90$ & 3 & 3.0 & 6 & 6.0 \\
\hline$>0.90$ & 97 & 97.0 & 94 & 94.0 \\
\hline Total & $\mathbf{1 0 0}$ & $\mathbf{1 0 0 . 0}$ & $\mathbf{1 0 0}$ & $\mathbf{1 0 0 . 0}$ \\
\hline Mean \pm SD & \multicolumn{2}{|c|}{$0.96 \pm 0.02^{\text {a }}$} & \multicolumn{2}{|c|}{$0.94 \pm 0.03^{\mathbf{b}}$} \\
\hline $\begin{array}{r}\text { Table 5. Relationship between Waist:Hip Ratio (WHR) } \\
\text { distributions among Study Groups }\end{array}$ \\
\hline
\end{tabular}

No: Number of subjects; \%: Percentage; SD: Standard deviation. Group I: Coronary artery disease cases; Group II: Subjects without CAD (controls). BMI distribution significantly differ from respective group (Values with different superscripts ' $a$, b' were significantly different from each other $\mathrm{p}<0.05$ ) (Paired t-test done).

\section{DISCUSSION}

The present study was designed as hospital-based descriptive comparative study to assess the role of various anthropometric risk factors in the occurrence of coronary artery disease. A total of 200 subjects (100 cases and 100 controls) were studied. Among the total 100 cases, 70 were males and 30 were females, male predominance has been also reported by Zodpay et al.10 Singh RB et al also observed that prevalence of CAD was significantly $(\mathrm{P}<0.001)$ higher in men as compared to women in both urban $(11 \%$ vs. $6.9 \%)$ and rural ( $3.9 \%$ vs. $2.6 \%$ ), areas respectively. ${ }^{11}$ The mean age of cases was $49.85 \pm 7.25$ years, largest number of cases were present in the age group of 41 - 50 years (51\%) followed by 51 - 60 years (39\%), whereas $10 \%$ of the cases had faced their first attack of CAD before crossing the 40 of their life, which is well-correlated with the findings of Zodpay et al.10 
BMI is highly correlated with body weight and is frequently used as a measure of body fitness in large epidemiological studies. As per literature, the definition of overweight and obesity on the basis of BMI values is somewhat confusing because different studies have used different criteria for it. According to world health organisation, subjects with BMI between $25-30 \mathrm{~kg} / \mathrm{m}^{2}$ are overweight and subjects with BMI $>30 \mathrm{~kg} / \mathrm{m}^{2}$ are obese. It is now clear that both genetic and environmental factors play an important role in obesity within the context of energy imbalance. Energy imbalance may be caused by an increase in energy intake, a decrease in energy expenditure or both. In the Framingham offspring study, BMI was strongly related to age and in men the increase in BMI with the age reached a plateau at the age of 50 years, but in women there was a constant increase in BMI with age through all age groups. ${ }^{12}$ In the study done by Westphal $\mathrm{AB}$ et al found that in adults, the prevalence of $\mathrm{BMI}>30 \mathrm{~kg} / \mathrm{m}^{2}$ gradually increased with decreasing percentile of height, whereas in children and adolescents a positive association between height and weight was observed.13 In the study done by Nordestgaard BG et al, every $4 \mathrm{~kg} / \mathrm{m}^{2}$ increase in BMI, observational estimates suggested a $20 \%$ increase in odds ratio for CHD, while casual estimates suggested a $52 \%$ increase. These data add evidence to support a causal link between increased BMI and CHD risk, though mechanism may ultimately be through intermediate factors like hypertension, dyslipidaemia and diabetes. ${ }^{14}$ In the study done by Akter SFU et al at rural setting in Malaysia found that BMI was $26.2 \mathrm{~kg} / \mathrm{m}^{2}$, prevalence of obesity increased with increasing age. They concluded that BMI can indicate and estimate population-specific risks for noncommunicable diseases including cardiovascular disease. The effect of obesity is due to its adverse influence on blood pressure. ${ }^{15}$ In the present study, mean BMI is $27.89 \mathrm{~kg} / \mathrm{m}^{2}$.

In the study done by Vishwanath $\mathrm{P}$ et al, it was found that BMI showed a significant correlation with lipid profile along with increased WHR and it was concluded that non-invasive anthropometric parameters can be used as screening tool for lipid profile abnormalities, 7,16 which was similar to the study done by Manjareeka $\mathrm{M}$ et al. ${ }^{17}$ Zhang $\mathrm{X}$ et al found that BMI, WC, WHR were all positively associated with the risk of CHD in Chinese women. ${ }^{18}$ In the study done on Turkish adults it was seen that BMI, WHR, WC and HC were significantly correlated with each other and were good predictors for cardiometabolic risk factors. ${ }^{19}$ In the study ${ }^{20}$ done on Tehranian adults the cut-off for WHR was 0.97 which is in close agreement with present study, the value being 0.96 . In the study done on Chinese women it was found that WHR was positively associated with the risk of CHD in both younger and older women, while other indices like BMI and WC were related to CHD risk primarily among younger women. ${ }^{18}$ In contrast to the study done by Brenner et al on Canadian adults who found $\mathrm{WC}$ to be a strong predictor of cardiometabolic health than BMI,21 in this study it was found that BMI $(p=0.0001)$ and WHR $(p=0.001)$ to be strong predictors compared to WC (0.0005). Similarly, Badaruddoza et al concluded that WHR and BMI are strong indicators for CAD risk factors. ${ }^{22}$

BMI, WC and WHR are the indicators for central adiposity which is a risk factor for cardiovascular disease. Multiple biologic mechanisms have been implicated in mediating adverse health effects of excess adiposity; however, the exact pathways are unknown. Visceral fat may be more sensitive to lipolysis compared with subcutaneous fat, thereby preferentially increasing circulating free fatty acid levels. Other proposed mechanisms involve secretion of adipokines, which may differ by fat storage site. ${ }^{23}$

\section{CONCLUSION}

The relationship between anthropometric parameters like BMI, WC and WHR to coronary artery disease indicates strong predictor in onset of disease. So these can be used as simple measures to identify those having these risk factors and subject them to appropriate interventions.

\section{REFERENCES}

[1] World Health Report: reducing risks, promoting healthy life. Geneva: World Health Organization 2002.

[2] Gupta R. Burden of coronary heart disease in India. Indian Heart J 2005;57(6):632-8.

[3] Prevention of coronary heart disease. Report of a WHO Expert Committee. WHO, Geneva. Tech Rep Ser 1982;678:8.

[4] Wannamethee SG, Shaper AG, Whincup PH, et al. Adult height, stroke and coronary heart disease. Am J Epidemiol 1998;148(11):1069-76.

[5] Forsen T, Eriksson J, Qiao Q, et al. Short stature and coronary heart disease: a 35-year follow-up of the Finnish cohorts of The Seven Countries Study. J Internal Med 2000;248(4):326-32.

[6] Paajanen TA, Oksala NK, Kuukasjärvi P, et al. Short stature is associated with coronary heart disease: a systematic review of the literature and a metaanalysis. European Heart Journal 2010;31(14):18029.

[7] Harwalkar VS, Panjakash S. A study on relationship of stature to coronary artery disease risk factors in cases and controls. Int J Anat Res 2017;5(2.3):3997-4001.

[8] Rose GA, Blackburn H, Gillum RF, et al. Cardiovascular survey methods. $2^{\text {nd }}$ edn. WHO monograph series no. 56. Geneva: World Health Organization 1982.

[9] Deurenberg P, Weststrate JA, Seidell JC. Body mass index as a measure of body fatness: age- and sexspecific prediction formulas. $\mathrm{Br} \mathrm{J}$ Nutr 1991;65(2):105-14.

[10] Zodpey SP, Kulkarni HR, Vasudeo ND, et al. Risk factors for coronary heart disease: a case control study. Indian J Commun Med 1998;23:7-14.

[11] Singh RB, Sharma JP, Rastogi V, et al. Prevalence of coronary artery disease and coronary risk factors in rural and urban population of north India. Eur Heart J 1997;18(11):1728-35.

[12] Lamon-Fava S, Wilson PW, Schaefer EJ. Impact of body mass index on coronary heart disease risk factors in men and women. The Framingham Offspring Study. Arterioscler Thromb Vasc Biol 1996;16(12):1509-15.

[13] Bosy-Westphal A, Plachta-Danielzik S, Dorhofer RP, et al. Short stature and obesity: positive association in adults but inverse association in children and adolescents. Brit J Nutr 2009;102(3):453-61. 
[14] Nordestgaard BG, Palmer TM, Benn M, et al. The effect of elevated body mass index on ischemic heart disease risk: casual estimates from a mendelian randomization approach. PLoS Med 2012;9(5): e1001212.

[15] Akter SFU, Fauzi ARM, Nordin MS, et al. Prevalence of cardiovascular risk factors in a selected community at Kuantan, Pahang, Malaysia. Int J Med and Med Sci 2010;2(10):322-8.

[16] Vishwanath P, Prashant A, Acharya A, et al. Use of anthropometric indices as simple predictors of deranged lipid profile and at risk population for future cardiovascular events. Int J Health Allied Sci 2012;1(1):8-12.

[17] Manjareeka M, Nanda S, Mishra J, et al. Correlation between anthropometry and lipid profile in healthy subjects of Eastern India. J Mid-Life Health 2015;6(4):164-8.

[18] Zhang X, Shu XO, Gao YT, et al. Anthropometric predictors of coronary heart disease in Chinese women. Int J Obes Relat Metab Disord 2004;28(6):734-40.
[19] Krakauer NY, Krakauer JC. An anthropometric risk index based on combining height, weight, waist and hip measurements. Article ID 8094275, J Obes 2016;2016:1-9.

[20] Mirmiran P, Esmaillzadeh A, Azizi F. Detection of cardiovascular risk factors by anthropometric measures in Tehranian adults: receiver operating characteristic (ROC) curve analysis. Eur J Clin Nutr 2004;58(8):1110-8.

[21] Brenner DR, Tepylo K, Eny KM, et al. Comparison of body mass index and waist circumference as predictors of cardiometabolic health in a population of young Canadian adults. Diabetol Metab Syndr 2010;2(1):28.

[22] Badaruddoza, Kaur N, Barna B. Inter-relationship of waist-to-hip ratio (WHR), body mass index (BMI) and subcutaneous fat with blood pressure among university-going Punjabi Sikh and Hindu females. Int J Med Med Sci 2010;2(1):5-11.

[23] Gelber RP, Gaziano JM, Orav EJ, et al. Measures of obesity and cardiovascular risk among men and women. J Am Coll Cardiol 2008;52(8):605-15. 